\title{
30 Responding to students living with domestic and family violence
}

\author{
Larissa Fogden and Cathy Humphreys
}

\section{How to use this policy}

Students of all ages experience domestic and family violence (DFV), regardless of gender, class, race or religion. Working with children and young people every day, school staff are ideally placed to identify and respond to students living with DFV. However, schools can only respond effectively to students when staff hold the knowledge and confidence to not only identify DFV but to implement ongoing support strategies and refer on to appropriate external services. As such, this policy focuses on building staff knowledge by outlining clear evidence-based processes for responding to students who are suspected of or have disclosed living with DFV. This policy also encourages collaboration with local community support services in order to build referral pathways and create future opportunities for collaboration with services outside of the education sector. This policy is intentionally broad and school policy creators are encouraged to delete and build upon suggestions below to create a policy that best represents their school.

[To adapt and use this policy, delete or modify the text as indicated]

\section{[INSERT name of school] Responding to domestic and family violence policy}

\section{Rationale}

The adverse effects of domestic and family violence (DFV) upon the health, development and wellbeing outcomes of children and young people is well established (Carpenter \& Stacks, 2009; Holt, Buckley \& Whelan, 2008; Kimball, 2016). In relation to educational outcomes, exposure to DFV has the potential to negatively impact a wide range of educational outcomes, including mathematical, verbal and reading abilities, as well as levels of school engagement and attendance (Huth-Bocks et al., 2001; Kiesel et al., 2016; Schnurr \& Lohman, 2013; Thompson \& Whimper, 2010). However, when children and young people feel supported at school, schools can be protective against the impacts of DFV and contribute to building student resilience, self-esteem 
and healthy coping skills (Campo et al., 2014; Sterne \& Poole, 2010; Thompson \& Trice-Black, 2012).

Child and young person victim/survivors commonly describe two specific needs: to have someone to talk to about their experiences and to feel safe (Mullender et al., 2002). Often, children and young people identify teachers and other education professionals as people outside of their families who they would turn to when seeking support for DFV (Howarth et al., 2016). When school staff have the knowledge and skills to provide support to these students, children and young people are more likely to view school as a safe and neutral place where they can take a break from what is happening at home (Bracewell et al., 2020; Buckley et al., 2007).

When responding to DFV, educational staff are not expected to take on extra roles as social workers or other welfare staff. Instead, as Mullender and colleagues (2002) describe, effective school responses should create a "channel for children to gain access to welfare services outside of school, by opening up an early opportunity for them to confide that something is wrong" (p. 219). When disclosing to school staff, students may be speaking about their experiences of violence for the first time. They need to be responded to skilfully to ensure their experiences are validated and provided with appropriate follow-up actions (Sterne \& Poole, 2010).

However, staff within schools often lack the knowledge and training to confidently identify and appropriately respond to student victim/survivors (Peckover \& Trotter, 2015). Some teachers feel they do not know what to say or do when students disclose DFV or what the scope of their role in responding should involve (Davies \& Berger, 2019). School staff want clear guidelines on what to do next when DFV is identified, as well as up-to-date information about appropriate external support services (Lloyd, 2018; Sterne \& Poole, 2010).

This policy provides schools with guidance on how to fulfil these staff needs, in order to respond effectively to students living with DFV. However, it is important to emphasise that any school policy related to DFV must sit within a wider whole-of-school response to family violence, which builds gender equity and respectful attitudes, behaviours, structures and practices into the overall culture of the school (Gleeson, Kearney, Leung \& Brislane, 2015). DFV school policies must also be aligned with location and contextspecific mandatory reporting and information-sharing requirements. Schools should consider creating additional policies to guide responses to dating violence within adolescent relationships, as well as responses to students who perpetrate family violence.

Beyond this policy, schools should also consider ways of partnering with local family violence agencies to deliver interventions for student victim/ survivors at school, through the co-location of family violence workers or provision of group programs on site (Stanley et al., 2015). Evidence suggests that being able to access support at schools can greatly benefit students living with family violence (Mullender et al., 2002; Thompson et al., 2012). 
Throughout this policy, domestic and family violence is used, as this is the preferred terminology used within Australia. However, each country has its preferred terminology, and as such, this policy should be customised to reflect the school's geographical context. Living with or experiencing family violence is defined as directly experiencing physical violence, sexual violence, emotional abuse and coercive control, as well as exposure to family violence within the home, such as witnessing intimate partner violence between parents or caregivers. Non-offending caregiver refers to a student's caregiver (e.g., mother) who has not perpetrated family violence.

\section{Purpose}

The purpose of this policy is to outline the roles and actions undertaken by all educational staff to identify and respond to students living with family violence. It is essential that all staff working within a school have the knowledge and skills to respond appropriately to children and young people experiencing family violence.

\section{Scope}

This policy applies to all [INSERT name of school] staff.

[INSERT specific roles and responsibilities of individuals or teams]

\section{Policy statement}

\section{Maintaining awareness and increasing knowledge}

[INSERT name of school] provides training to all school employees related to

1) Identifying signs of domestic and family violence in children, young people and parents/caregivers;

2) How and where to document concerns about children (including observations) within the school's welfare system;

3) [INSERT name of school]'s process for responding to disclosures of domestic and family violence and providing ongoing support for affected students, including appropriate referral pathways into local support services;

4) Maintaining and upholding confidentiality related to student disclosures and circumstances;

5) Specific issues relating to risk and barriers to support experienced by diverse cohorts (Ellis, 2012; Sterne \& Poole, 2010; Young et al., 2008).

Newly employed staff complete this training as part of their employee induction process.

All staff members at [INSERT name of school] are provided with regular (e.g., once a school term) opportunities to participate in professional 


\section{Fogden \& Humphreys}

development sessions run by local family violence support services or other support services related to child abuse and neglect. These professional development sessions provide practical information to staff about what these services offer and how to refer children, young people and families to these services (Campo et al., 2014).

[INSERT name of school] displays information about local domestic and family violence support services (e.g., posters, brochures) in public and wellfrequented areas, such as reception areas and staffrooms (Sterne \& Poole, 2010).

Students are informed at regular intervals about the [INSERT name of school] confidentiality and information-sharing policies (e.g. at school assemblies), so that they know who they can talk to and under what circumstances the information they share with staff will be released to their parent/caregiver, child protection services, law enforcement or anyone else (Sterne \& Poole, 2010).

\section{Responding to students who are suspected to be or identified as living with family violence}

[INSERT name of school] has a designated team of staff members (inclusive of teachers, counsellors, psychologists, executive members, etc.) ${ }^{1}$ who hold responsibility for child welfare, specifically, issues related to domestic and family violence (Holt, 2015). This team, henceforth referred to as the $F V$ Response Team, meets regularly and is responsible for planning and implementing [INSERT name of school]'s responses to both newly and previously identified students living with domestic and family violence. The $F V$ Response Team also provides secondary consultation to staff and collaborates with external support services, as required (Davies \& Berger, 2019).

All information concerning a student's status as a victim/survivor of family violence is retained in the strictest confidence and only shared with other school staff as necessary to protect the student's safety and dignity (Bracewell et al., 2020).

When staff suspect that a student is experiencing family violence, as soon as possible, they:

1 Document evidence (e.g., observations) using the [INSERT name of school]'s internal welfare system;

2 Consult with the FV Response Team to plan an appropriate response.

When a student discloses to [INSERT name of school] staff that they are living with domestic and family violence, the responding staff member:

1 Listens closely and non-judgmentally to what the student is saying, reinforcing that the violence or abuse is not their fault. This may be the first time a student has disclosed their experiences; 
2 Informs the student that the responding staff member has a responsibility to inform specific other people about what the student has said;

3 Clearly outlines who the responding staff member will share the student's disclosure with:

a The student's non-offending caregiver (e.g., their mother);

b The $F V$ Response Team, letting the student know who is on this team so that the student knows exactly who their disclosure will be shared with;

c When appropriate, child protection agencies, depending on the nature of the student's disclosure and the responding staff member's mandatory reporting requirements;

4 Provides the student with opportunities to participate in decision-making related to what will happen next (Noble-Carr et al., 2020). For example, if appropriate:

a Ask the student if they are comfortable with any other staff members knowing about their disclosure. If there are, and the student consents, these staff members may be invited to join FV Response Team meetings in relation to the student;

b Ask the student if they would like to be present when their nonoffending caregiver is contacted;

5 Outlines clear steps to the students as to what will happen next (e.g. "I am going to speak to [INSERT name of teacher] or [FV Response Team] then talk to you tomorrow"), without making promises to the student that they cannot keep (e.g., "I'll keep you safe").

All [INSERT name of school] staff involved in responding to family violence disclosures are offered the opportunity to debrief and access support either internally from supervisory staff or externally (e.g., accessing Employee Assistance Programs) (Ellis, 2012).

All [INSERT name of school] staff members document any concerns about, or disclosures from, students living with domestic and family violence within the [INSERT name of school]'s internal welfare system. Student disclosures and/or staff observations must be documented as soon as possible after the event, with staff members including as much detail as possible. This documentation may be used later in legal proceedings related to family violence (Cooper et al., 2012).

\section{Support for students living with family violence}

The FV Response Team collaborates with [INSERT name of school] student victim/survivors (and/or non-offending caregivers, when appropriate) to create an Individual Support Plan. Through this Plan, students can access provisions, such as (Bracewell et al., 2020; Lloyd, 2018): 


\section{Fogden \& Humphreys}

- Adjustments to class schedules;

- Extensions on homework or assignment due dates;

- A safe and quiet space with access to a computer and internet that can be accessed as needed outside of school hours (e.g., before or after school) to complete homework. This is particularly helpful for students living in crisis or refuge accommodation who may not have access to computers or the internet;

- Additional learning support in the form of lunchtime or outside of school hours sessions.

Individual Support Plans are living documents and are modified as students' circumstances and needs change over time.

\section{Maintaining safety for students living with family violence}

[INSERT name of school] adheres to the following guidelines (see Cooper et al., 2012; Sterne \& Poole, 2010) to maintain safety and confidentiality, dependent on the student's circumstances:

- Copies of legal orders related to parenting arrangements and intervention orders are obtained and kept with the student's file;

- Information about students is never given out over the phone. If someone contacts the school to ask whether children attend the school, this information is neither confirmed nor denied until consent is provided by the non-offending caregiver;

- Photographs of students experiencing DFV are not published in local newspapers or on websites, unless the non-offending caregiver has provided consent.

The FV Response Team works with the non-offending caregiver (and the student, when appropriate) to create a clear plan (see Cooper et al., 2012; Sterne \& Poole, 2010) for:

- How a student travels to and from school. Options are provided for families. For example, non-offending caregivers can collect students from the front office (indoors and out of sight) rather than the playground;

- How to respond if a parent who has perpetrated violence arrives at the school to see the child;

- How to respond if a parent who has perpetrated violence contacts the school asking for information.

This plan is documented and kept within the student's file. 


\section{Rating of evidence base}

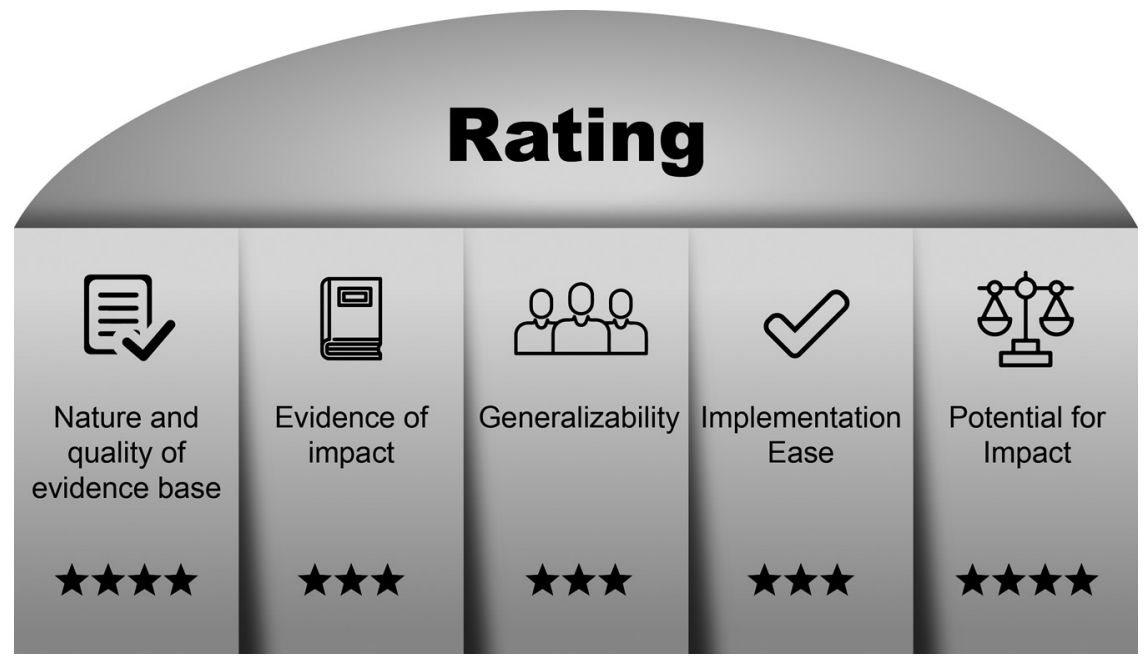

Figure 30.1. Students Living with Domestic and Family Violence Rating of Evidence.

\section{Authorship}

Larissa Fogden, The University of Melbourne

Professor Cathy Humphreys, The University of Melbourne

[INSERT RELEVANT STAFF MEMBERS]

\section{Related policy and documents}

\section{[INSERT RELEVANT POLICY AND DOCUMENTS]}

Mandatory reporting policies

Information sharing policies

\section{Date of ratification}

This policy was ratified on the [INSERT DATE].

\section{Date of review}

This policy will be reviewed by [INSERT DATE].

\section{Note}

1 Wellbeing staff teams, panels or groups may already exist within schools who are able to incorporate these activities into their overall roles. 


\section{References}

Buckley, H., Holt, S., \& Whelan, S. (2007). Listen to me! Children's experiences of domestic violence. Child Abuse Review, 16(5), 296-310.

Bracewell, K., Larkins, C., Radford, L., \& Stanley, N. (2020). Educational opportunities and obstacles for teenagers living in domestic violence refuges. Child Abuse Review, 29(2), 130-143.

Campo, M., Kaspiew, R., Moore, S., \& Tayton, S. (2014). Children affected by family violence: A review of domestic and family violence prevention, early intervention and response services. Melbourne: Australian Institute of Family Studies.

Carpenter, G. L., \& Stacks, A. M. (2009). Developmental effects of exposure to intimate partner violence in early childhood: A review of the literature. Children and Youth Services Review, 31, 831-839.

Cooper, D., Perkins, K., \& Couper, G. (2012). Family law issues and schools: Guidance for Australian educators. International Journal of Law \& Education, 17(1), 23-38.

Davies, S., \& Berger, E. (2019). Teachers' experiences in responding to students' exposure to domestic violence. Australian Journal of Teacher Education, 44(11), 96-109.

Ellis, G. (2012). The impact on teachers of supporting children exposed to domestic abuse. Educational \& Child Psychology, 29(4), 109-120.

Gleeson, C., Kearney, S., Leung, L., \& Brislane, J. (2015). Respectful relationships education in schools: Evidence paper. Melbourne: Our Watch.

Holt, S. L. (2015). An exploration of the impacts that experiencing domestic violence can have on a child's primary school education: View of educational staff. British Journal of Community Justice, 13(2), 7-26.

Holt, S., Buckley, H., \& Whelan, S. (2008). The impact of exposure to domestic violence on children and young people: A review of the literature. Child Abuse and Neglect, 32(8), 797-810.

Howarth, E., Moore, T. H. M., Welton, N. J., Lewis, N., Stanley, N., MacMillan, H., Shaw, A., Hester, M., Bryden, P., \& Feder, G. (2016). IMPRoving outcomes for children exposed to domestic ViolencE (IMPROVE): An evidence synthesis. Public Health Research, 4(10). https://www.ncbi.nlm.nih.gov/books/NBK401353/pdf/Book shelf_NBK401353.pdf

Huth-Bocks, A. C., Levendosky, A. A., \& Semel, M. A. (2001). The direct and indirect effects of domestic violence on young children's intellectual functioning. Journal of Family Violence, 16(3), 269-290.

Kiesel, L. R., Piescher, K. N., \& Edleson, J. L. (2016). The relationship between child maltreatment, intimate partner violence exposure, and academic performance. Journal of Public Child Welfare, 10(4), 434-456.

Kimball, E. (2016). Edleson revisited: Reviewing children's witnessing of domestic violence 15 years later. Journal of Family Violence, 31(5), 625-637.

Lloyd, M. (2018). Domestic violence and education: Examining the impact of domestic violence on young children, children, and young people and the potential role of schools. Frontiers in Psychology, 9(2094), 1-11.

Mullender, A., Hague, G., Imam, U., Kelly, L., Malos, E., \& Regan, L. (2002). Children's perspectives on domestic violence. London: SAGE Publications.

Noble-Carr, D., Moore, T., \& McArthur, M. (2020). Children's experiences and needs in relation to domestic and family violence: Findings from a meta-synthesis. Child \& Family Social Work, 25, 182-191. 
Peckover, S., \& Trotter, F. (2015). Keeping the focus on children: the challenges of safeguarding children affected by domestic abuse. Health and Social Care in the Community, 23(4), 399-407.

Schnurr, M. P., \& Lohman, B. J. (2013). Longitudinal impact of toddlers' exposure to domestic violence. Journal of Aggression, Maltreatment \& Trauma, 22(9), 1015-1031.

Stanley, N., Ellis, J., Farrelly, N., Hollinghurst, S., \& Downe, S. (2015). Preventing domestic abuse for children and young people: A review of school-based interventions. Child and Youth Services Review, 59, 120-131.

Sterne, A., \& Poole, L. (2010). Domestic violence and children: A handbook for schools and early settings. New York, NY: Routledge.

Thompson, E. H., \& Trice-Black, S. (2012). School-based group interventions for children exposed to domestic violence. Journal of Family Violence, 27, 233-241.

Thompson, R., \& Whimper, L. A. (2010). Exposure to family violence and reading level of early adolescents. Journal of Aggression, Maltreatment \& Trauma, 19(7), 721-733.

Young, H., Mancuso, A., Faherty, E., Dorman, S., \& Umbrell, J. (2008). Helping child victims of family violence through school personnel: An evaluation of a training programme. Journal of Aggression, Maltreatment \& Trauma, 16(2), 144-163. 